\title{
Power conversion with SiC devices at extremely high ambient temperatures
}

\section{AUTHOR(S):}

Funaki, T; Balda, JC; Junghans, J; Kashyap, AS; Mantooth, HA; Barlow, F; Kimoto, T; Hikihara, T

\section{CITATION:}

Funaki, T ...[et al]. Power conversion with SiC devices at extremely high ambient temperatures. IEEE TRANSACTIONS ON POWER ELECTRONICS 2007, 22(4): 1321-1329

\section{ISSUE DATE:}

2007-07

URL:

http://hdl.handle.net/2433/50531

\section{RIGHT:}

(c)2007 IEEE. Personal use of this material is permitted. However, permission to reprint/republish this material for advertising or promotional purposes or for creating new collective works for resale or redistribution to servers or lists, or to reuse any copyrighted component of this work in other works must be obtained from the IEEE. 


\section{Power Conversion With SiC Devices at Extremely High Ambient Temperatures}

Tsuyoshi Funaki, Member, IEEE, Juan Carlos Balda, Senior Member, IEEE, Jeremy Junghans, Member, IEEE, Avinash S. Kashyap, Student Member, IEEE, H. Alan Mantooth, Senior Member, IEEE, Fred Barlow, Member, IEEE, Tsunenobu Kimoto, Member, IEEE, and Takashi Hikihara, Member, IEEE

\begin{abstract}
This paper evaluates the capability of $\mathrm{SiC}$ power semiconductor devices, in particular JFET and Schottky barrier diodes (SBD) for application in high-temperature power electronics. SiC JFETs and SBDs were packaged in high temperature packages to measure the dc characteristics of these $\mathrm{SiC}$ devices at ambient temperatures ranging from $25^{\circ} \mathrm{C}$ (room temperature) up to $450{ }^{\circ} \mathrm{C}$. The results show that both devices can operate at $450{ }^{\circ} \mathrm{C}$, which is impossible for conventional Si devices, at the expense of significant derating. The current capability of the SiC SBD does not change with temperature, but as expected the JFET current decreases with rising temperatures. A $100 \mathrm{~V}, 25 \mathrm{~W}$ dc-dc converter is used as an example of a high-temperature power-electronics circuit because of circuit simplicity. The converter is designed and built in accordance with the static characteristics of the $\mathrm{SiC}$ devices measured under extremely high ambient temperatures, and then tested up to an ambient temperature of $400{ }^{\circ} \mathrm{C}$. The conduction loss of the $\mathrm{SiC}$ JFET increases slightly with increasing temperatures, as predicted from its dc characteristics, but its switching characteristics hardly change. Thus, $\mathrm{SiC}$ devices are well suited for operation in harsh temperature environments like aerospace and automotive applications.
\end{abstract}

Index Terms-dc-dc converter circuit, device characterization, high temperature operation, packaging, silicon carbide $(\mathrm{SiC}) \mathrm{de}$ vice.

\section{INTRODUCTION}

$\mathbf{S}$ ILICON CARBIDE ( $\mathrm{SiC}$ ) has several superior characteristics over silicon $(\mathrm{Si})$ when used as a semiconductor material [1]-[6]. In particular, $\mathrm{SiC}$ semiconductor devices are expected

Manuscript received February 10, 2006. The work of T. Funaki was supported in part by the Ministry of Education, Culture, Sports, Sciences and Technology in Japan, the Grant-in-Aid for Scientific Research 17686024 and in part by the 21 st Century COE Program 14213201, Japan. The work of J. C. Balda, J. Junghans, A. Kashyap, H. A. Mantooth, and F. Barlow was supported in part by the Office of Naval Research under Award N00014-04-1-0603 and in part by the National Science Foundation under Award ECS-0424411. Recommended by Associate Editor Y. C. Liang. This paper was presented at the IEEE 36th Annu. Power Electronics Specialists Conference (PESC), Recife, Brazil, June 12-16, 2005, pp. 2030-2035.

T. Funaki and T. Hikihara are with Department of Electrical Engineering, Graduate School of Engineering, Kyoto University, Kyoto 615-8510, Japan (e-mail: funaki@kuee.kyoto-u.ac.jp; hikihara@kuee.kyoto-u.ac.jp).

J. C. Balda, A. S. Kashyap, and H. A. Mantooth are with Department of Electrical Engineering, University of Arkansas, Fayetteville, AR 72701 USA (e-mail: jbalda@uark.edu; akashya@uark.edu; mantooth@uark.edu).

J. Junghans is with RF Power Devices Group, Northrop Grumman Electronic Systems, Baltimore, MD 21203 USA (e-mail: jeremy.junghans@ngc.com).

F. Barlow is with the Electrical and Computer Engineering Department, University of Idaho, Moscow, ID 83844 USA (e-mail: fbarlow@uidaho.edu).

T. Kimoto is with the Department of Electronic Science and Engineering, Graduate School of Engineering, Kyoto University, Kyoto 615-8510, Japan (e-mail: kimoto@kuee.kyoto-u.ac.jp).

Digital Object Identifier 10.1109/TPEL.2007.900561
TABLE I

SiC DEVICE PARAMETERS

\begin{tabular}{|l|l|l|}
\hline Packaging & Ni plated JEDEC, TO-258, 3 mil Al wire bond \\
\hline \multirow{5}{*}{ SiC JFET } & Manufacturer & SiCED \\
& Type & Vertical JFET, 2.8 m \\
& Rated current $\left(\mathrm{I}_{\mathrm{ds}}\right)$ & $2.5 \mathrm{~A}$ \\
& Rated voltage $\left(\mathrm{V}_{\mathrm{ds}}\right)$ & $1200 \mathrm{~V}$ \\
\hline \multirow{5}{*}{ SiC SBD } & Manufacturer & Cree \\
& Type & CPWR-0600S004 \\
& Rated current & $4 \mathrm{~A}$ \\
& Rated voltage & $600 \mathrm{~V}$ \\
& Rated temperature & $-55 \sim+175^{\circ} \mathrm{C}$ \\
\hline
\end{tabular}

to have high temperature, high speed and high voltage operation capabilities [7], which are attributed to the wide bandgap properties of $\mathrm{SiC}$. These advantages cannot all be obtained with conventional Si-based semiconductor devices. This paper focuses on the high temperature operation capability of $\mathrm{SiC}$ devices and their switching characteristics in a dc-dc buck converter. $\mathrm{SiC}$ JFETs and Schottky barrier diodes (SBD) are specifically addressed in this work.

Several publications have indicated that $\mathrm{SiC}$ semiconductor devices are suitable for high temperature operation [8]-[13], [15], [16]. However, most publications cover the study of low power devices like op-amps [8], sensors [9], or integrated circuits [10]. There are a few studies on power converters, but they are limited to temperatures under $250{ }^{\circ} \mathrm{C}$ [11]-[15]. Furthermore, there has been no report on the operation of gate controllable devices such as JFETs at extremely high ambient temperatures. The two main reasons are that (a) the SiC JFET is still under development, and (b) the difficulty of packaging bare die for high temperature operation. The latter requires not only that the $\mathrm{SiC}$ bare die be capable of operation at high temperatures, but also the package material (including the die attach and wire bonds) and the auxiliary circuit components (e.g., gate driver). Otherwise, the converter can only operate up to ambient temperatures no greater than $250{ }^{\circ} \mathrm{C}$.

$\mathrm{SiC}$ JFETs and SBDs were packaged in dedicated thermally stable packages. The dc characteristics of the SiC JFET and SBD under extremely high ambient temperature conditions up to $450{ }^{\circ} \mathrm{C}$ were then evaluated using an automated experimental setup for high temperature measurements. The current ratings of the dc-dc buck converter were determined from the experimental results since derating occurs in the SiC JFET with increasing temperatures. The converter inductor was designed and built using a high-temperature toroidal magnetic core and hightemperature wires. Testing was done up to ambient temperatures of $400{ }^{\circ} \mathrm{C}$ using a resistive load in order to evaluate the switching 


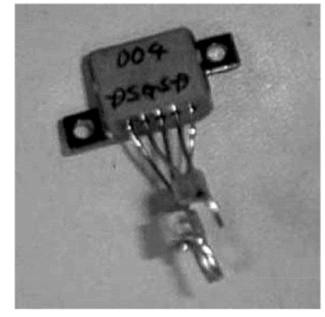

(a)

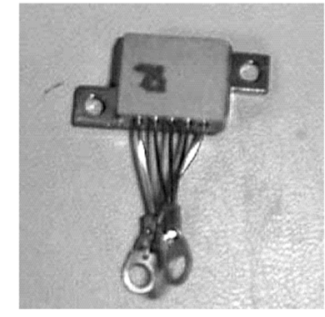

(b)

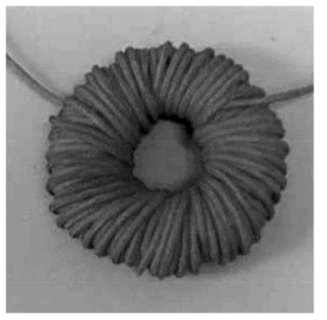

(c)

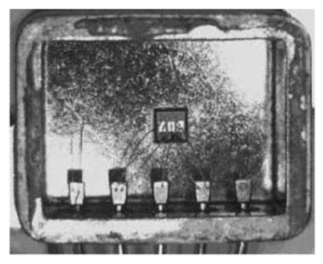

(d)

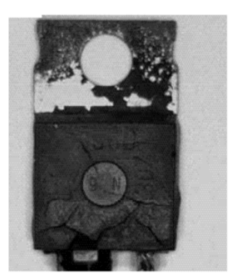

(e)

Fig. 1. SiC devices and inductor for high temperature operation. (a) SiC JFET, (b) SiC SBD, (c) inductor, (d) SiC JFET chip after $450^{\circ} \mathrm{C}$ operation, (e) conventional plastic package of $\mathrm{SiC} \mathrm{SBD}$ after $400^{\circ} \mathrm{C}$ experiment (destroyed).

characteristics of $\mathrm{SiC}$ devices within the converter circuit and clarified the difficulty in designing a converter for operation in harsh temperatures. Presently, some components such as gate drivers and filter capacitors cannot be operated up to ambient temperatures of $400{ }^{\circ} \mathrm{C}$; so these components were placed outside the oven. But, the operation of the main conversion circuit consists of $\mathrm{SiC}$ devices for $400{ }^{\circ} \mathrm{C}$ is feasible for locally heated conditions. The experiments in this paper are simply an evaluation of high-temperature effects in $\mathrm{SiC}$ devices so designers are able to address device derating and tradeoffs when designing a specific high-temperature application. For completeness, [16] showed the feasibility of an entire converter system operated up to $250{ }^{\circ} \mathrm{C}$, including controller and gate drivers.

This paper is organized as follows: Section II describes the SiC JFET, SiC SBD and inductor; Section III presents the dc characteristics of the $\mathrm{SiC}$ devices under high ambient temperatures; Section IV evaluates the converter operation under high ambient temperatures; and finally, Section V provides the conclusions drawn from this work.

\section{DESCRIPTION OF THE HIGH TEMPERATURE COMPONENTS}

A dc-dc buck converter is one of the simplest power conversion circuits consisting of a switching device, a diode, an inductor, and input and output capacitors. The inductor enables evaluating the dynamic characteristics of switching devices in a practical circuit.

The $1200 \mathrm{~V}, 2.5 \mathrm{~A}$ SiC JFET used in this work is a verticaltopology $2.8 \mathrm{~mm}^{2}$ bare die research sample supplied by SiCED. This JFET with a Si MOSFET is commercially available as a cascode device packaged in the general plastic IXYS i4 package [17], [18]. The SiC 600 V, 4 A SBD is commercially available from Cree and has a surface area of $1.9 \mathrm{~mm}^{2}$ and the operation is guaranteed up to a maximum temperature of $175^{\circ} \mathrm{C}$. The basic specifications of these SiC devices are given in Table I.

The bare die of the SiC JFET and SBD were packaged in Ni-plated JEDEC TO-258 packages to allow high-temperature
TABLE II

HIGH TEMPERATURE INDUCTOR SPECIFICATIONS

\begin{tabular}{|l|l|}
\hline Inductance & $0.6 \mathrm{mH}$ \\
Core & Kool Mu-77908-A7 \\
Permeability & $26 \mu$ \\
Curie temp. & $500^{\circ} \mathrm{C}$ \\
Windings & $124 \mathrm{turn}$ \\
Size & $0.508 \mathrm{~mm}^{2}(27 \%$ Ni-clad Cu $)$ \\
Insulator & $0.686 \mathrm{~mm}$ \\
Jacket & $0.203 \mathrm{~mm}$ \\
Nominal OD & $2.74 \mathrm{~mm}$ \\
Jacket & Mica Insulation /Fiberglass Wrap \\
\hline
\end{tabular}

operation. The die have metallization on their top and back surfaces as well as terminal contacts. The JFET drain and SBD cathode contacts were attached to the bottom of the package. The JFET source and gate contacts and the SBD anode contacts were wire bonded to the respective terminals in the package with 3-mil Al wire. Fig. 1(a) and (b) shows the packaged SiC JFET and SBD, respectively.

The inductor was built using the Kool-Mu 97907-A7 hightemperature magnetic toroidal core from Magnetics Inc. The core is made of ferrous alloy powder with a relative permeability of 26 and a Curie temperature of $500{ }^{\circ} \mathrm{C}$. The inductor has an inductance of $0.6 \mathrm{mH}$ with 124 turns of high-temperature wire that can withstand temperatures up to $450{ }^{\circ} \mathrm{C}$. Fig. 1(c) shows the inductor, and its specifications are summarized in Table II. Capacitors capable of operating at $400{ }^{\circ} \mathrm{C}$ were not available to the research team; in fact, this in itself is ongoing research at the present time. Thus, the converter circuit does not have the filter capacitors typical of these converters. Fig. 1(d) gives the conditions of the die attach and wire bond for the SiC JFET in the high-temperature package after high-temperature operation. No defect was found in the package and the device worked normally. However, a SiC SBD packaged in a conventional plastic package was damaged by high temperature exposure and malfunctioned as shown in Fig. 1(e). 


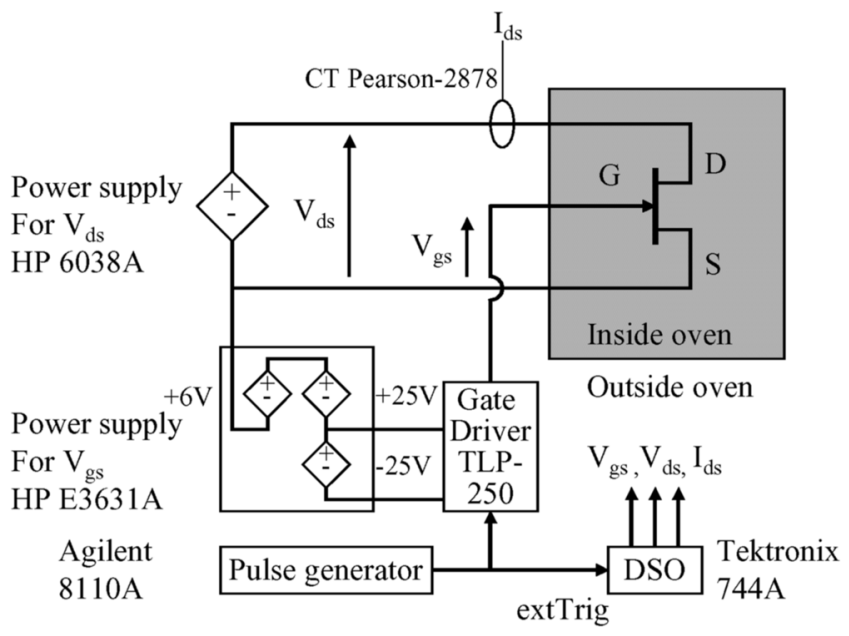

Fig. 2. Experimental setup for measuring temperature dependency of the $\mathrm{SiC}$ JFET de characteristics.

\section{DC Characteristics OF SiC DeVICES UNDER High TEMPERATURE CONDITIONS}

\section{A. Measurement Setup}

Fig. 2 illustrates the configuration of the experimental setup used to measure the dc characteristics of the SiC JFET under a wide range of ambient temperatures. The $\mathrm{SiC}$ device under test (DUT) is placed inside a temperature-controlled oven. All the measurement equipment and power supplies to the device are controlled by a PC using LabView and an IEEE-488 (GPIB) link. The measurements were performed automatically and the data was collected and processed within the PC. There are two power sources; one to supply the drain-source voltage $\left(V_{\mathrm{ds}}\right)$ and the other to supply the gate-source voltage $\left(V_{\mathrm{gs}}\right)$. The drain-source voltage $V_{\mathrm{ds}}$ is swept from $0 \mathrm{~V}$ to $20 \mathrm{~V}$ for different values of the gate-source voltage $V_{\mathrm{gs}}$. The power supply for $V_{\mathrm{gs}}$ provides voltages in two levels, the higher one is used for the gate voltage $\left(V_{\mathrm{gs}}\right)$, and the lower one is used to switch off the JFET. The gate voltage is imposed on the DUT through an optically-isolated gate driver, the TLP-250 from Toshiba Corp. A pulse generator that can produce arbitrary widths of the gate pulses is set to output $40 \mu$ s ON pulses to prevent self-heating of the device by conduction current. A digital storage oscilloscope is triggered by the gate signal produced by the pulse generator via an external trigger terminal (extTrig) and performs data acquisition. The PC executes part of the numerical processing and data storage tasks, which are programmed in LabView.

\section{B. DC characteristics of SiC JFET}

Fig. 3 illustrates the $\mathrm{I}_{\mathrm{ds}}-\mathrm{V}_{\mathrm{ds}}$ characteristics of the tested SiC JFET with the gate voltage $V_{\text {gs }}$ as a parameter at $25^{\circ} \mathrm{C}$ (room temperature), $200{ }^{\circ} \mathrm{C}$ and $450{ }^{\circ} \mathrm{C}$ ambient temperatures. Fig. 3(a) illustrates that the SiC JFET has pentode-like dc characteristics at room temperature. The threshold gate voltage is approximately $V_{\mathrm{gs}}=-12 \mathrm{~V}$, the saturation current for $V_{\mathrm{gs}}=0 \mathrm{~V}$ is about $3.5 \mathrm{~A}$. The low drain-source resistance of approximately $1.33 \Omega\left(\sim 37 \mathrm{~m} \Omega-\mathrm{cm}^{2}\right)$ results in a steep slope in the linear region. The threshold gate voltage becomes approximately $V_{\text {gs }}=-13 \mathrm{~V}$ at $200^{\circ} \mathrm{C}$ [see Fig. 3(b)]. Fig. 3(c) shows the dc characteristics for an extremely high ambient temperature of $450{ }^{\circ} \mathrm{C}$, which is far beyond the temperature capability of $\mathrm{Si}$ devices (i.e., $175^{\circ} \mathrm{C}$ ). At this temperature, the pinch off drain voltage at $V_{\mathrm{gs}}=0 \mathrm{~V}$ becomes unclear. The output current saturates at a much lower values (e.g., down to $0.7 \mathrm{~A}$ from $3.5 \mathrm{~A}$ for the top curve), or $20 \%$ of the value at $25{ }^{\circ} \mathrm{C}$ (room temperature), and the drain-source resistance increases to $10.0 \Omega\left(\sim 278 \mathrm{~m} \Omega-\mathrm{cm}^{2}\right)$ in the linear region for $V_{\mathrm{gs}}=0 \mathrm{~V}$. The threshold gate voltage becomes slightly more negative to $V_{\mathrm{gs}}=-15 \mathrm{~V}$. The leakage current in the "OFF" condition of the SiC JFET when applying $V_{\mathrm{gs}}=-20 \mathrm{~V}$ is given in Fig. 3(d) to clarify the forward blocking capability to the change of temperature. It shows that the SiC JFET can remain in the "OFF" condition at $400{ }^{\circ} \mathrm{C}$, but the leakage current increases remarkably when the temperature exceeds $300{ }^{\circ} \mathrm{C}$. The designers of the converter should take into account this leakage current shift when they are expected to operate over $300{ }^{\circ} \mathrm{C}$.

Fig. 4(a) shows the dc characteristics at $V_{\mathrm{gs}}=0 \mathrm{~V}$ for different ambient temperatures. An analysis reveals that $(a)$ the pinch-off drain voltage shifted to higher values, and $(b)$ the drain current saturates at lower levels, both in accordance with increasing temperatures. In the case of the drain current, $3.5 \mathrm{~A}$ at room temperature, $2.2 \mathrm{~A}$ at $120^{\circ} \mathrm{C}, 1.4 \mathrm{~A}$ at $200^{\circ} \mathrm{C}, 1.0 \mathrm{~A}$ at $300^{\circ} \mathrm{C}$, and $0.7 \mathrm{~A}$ at $450^{\circ} \mathrm{C}$, for $V_{\mathrm{gs}}=0 \mathrm{~V}$. The temperature dependency of the saturated drain current at $V_{\mathrm{ds}}=20 \mathrm{~V}$ is shown in Fig. 4(b). The current drastically decreases as the ambient temperature increases for values below $200{ }^{\circ} \mathrm{C}$, but the changes become smaller for higher temperatures. These results indicate that the rated current of this JFET should be $0.7 \mathrm{~A}$ when this device is used in a circuit where its ambient temperature could be as high as $450{ }^{\circ} \mathrm{C}$. Based on these results, the design of the dc-dc buck converter will consider a lower current of $0.5 \mathrm{~A}$ to incorporate a safety margin. From Fig. 4(a) the voltage drop between the drain and source at $0.5 \mathrm{~A}$ changes from $0.7 \mathrm{~V}$ at 25 ${ }^{\circ} \mathrm{C}$ to $6 \mathrm{~V}$ at $450{ }^{\circ} \mathrm{C}$. Fig. 4(c) shows drain-source resistance as function of temperature for $I_{\mathrm{ds}}=0.5 \mathrm{~A}$ at the "ON" condition. The drain resistance at $450{ }^{\circ} \mathrm{C}$ becomes 10 times greater than those at $25^{\circ} \mathrm{C}$. However, operation at these high temperatures for $\mathrm{Si}$ devices is impossible and unfortunately, significant derating cannot be avoided for high-temperature applications. The SiC JFET does not require changing the gate circuitry with increasing temperatures since the threshold gate voltage changes by only a few Volts, thus making the device easy to use in high temperature applications.

\section{DC Characteristics of the SiC SBD}

Fig. 5(a) illustrates the $\mathrm{I}_{\mathrm{ak}}-\mathrm{V}_{\mathrm{ak}}$ characteristics of the $\mathrm{SiC}$ SBD for different ambient temperatures. The cut-in voltage of the diode decreases with rising temperatures due to the Schottky barrier height reduction with increasing temperature. The slope of the linear region of the characteristic curve, which resides in the region higher than the cut-in voltage, becomes shallower 


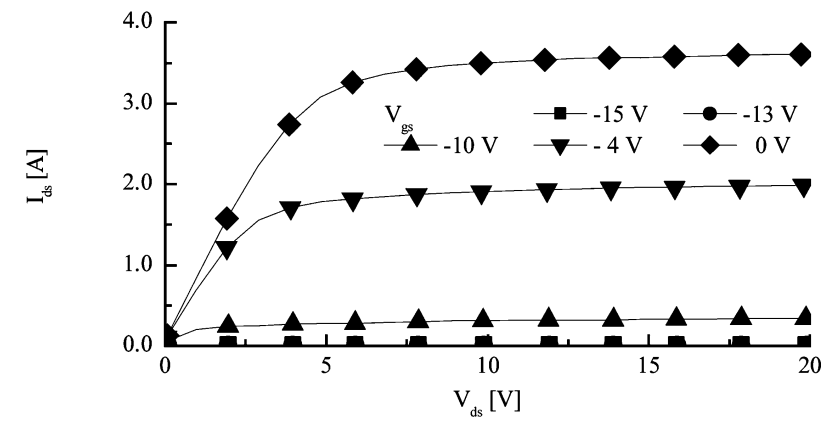

(a)

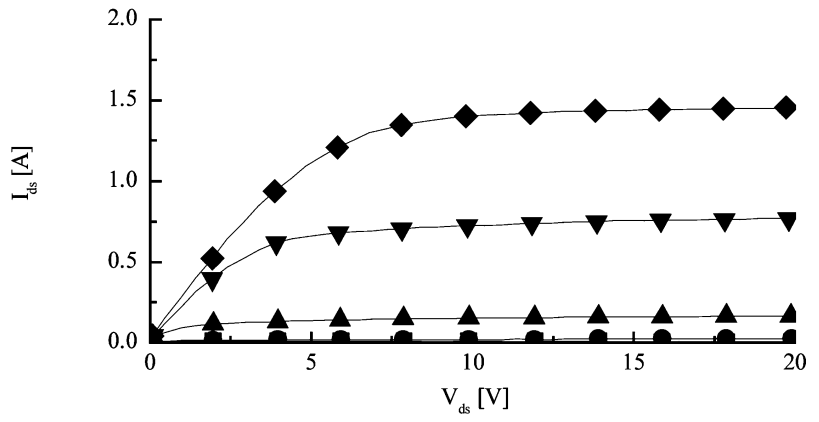

(b)

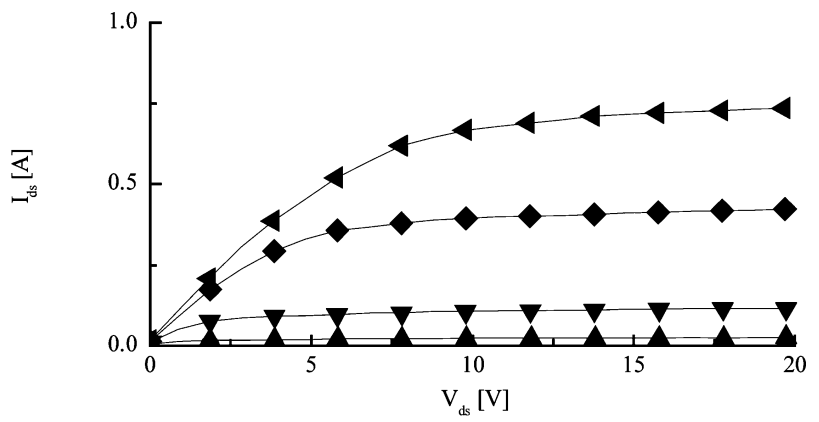

(c)

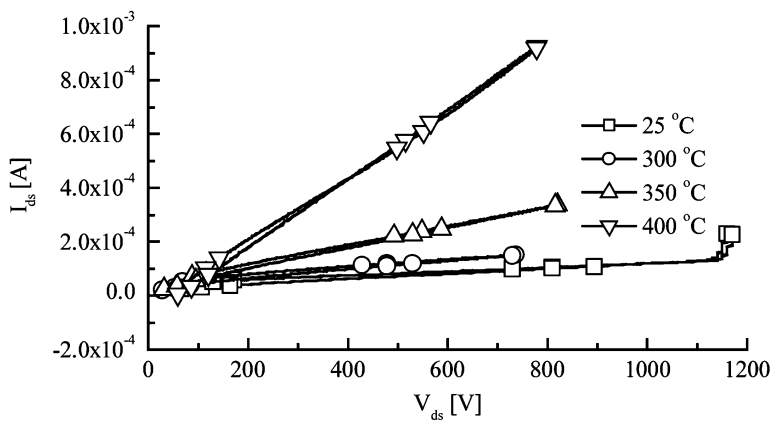

(d)

Fig. 3. DC characteristics of the SiC JFET for ambient temperatures as function of $\mathrm{V}_{\text {gs }}$. (a) $25^{\circ} \mathrm{C}$ (Room temperature), (b) $200^{\circ} \mathrm{C}$, (c) $450^{\circ} \mathrm{C}$, (d) forward blocking capability of SiC JFET for $\mathrm{V}_{g s}=-20 \mathrm{~V}$.

with rising temperatures. This means that the series resistance in the diode increases with rising temperatures.

Fig. 5(b) shows the forward voltage drop of the SiC SBD as function of temperature for $I_{\mathrm{ak}}=0.5 \mathrm{~A}$. The forward voltage drop changes nonlinearly due to the adverse effects of the cut-in voltage and series resistance changes with rising temperatures. However, these forward voltage drop changes are relatively small when compared to the absolute value of the forward voltage drop, and the variation with temperature is

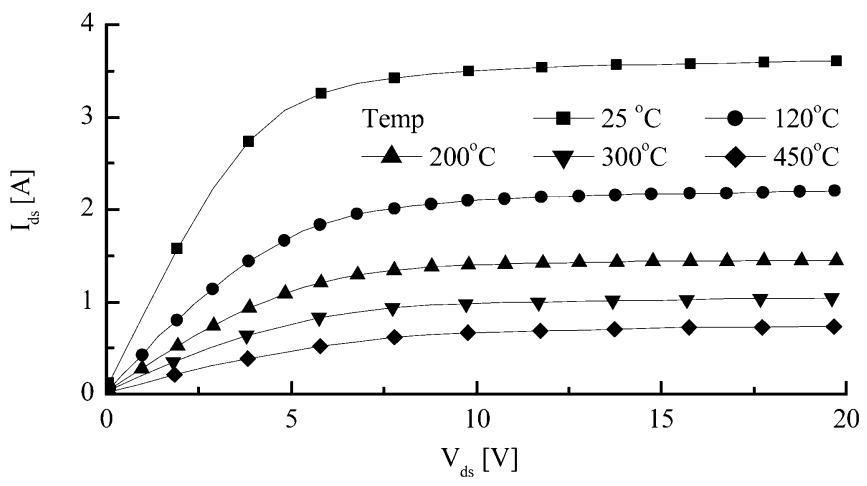

(a)

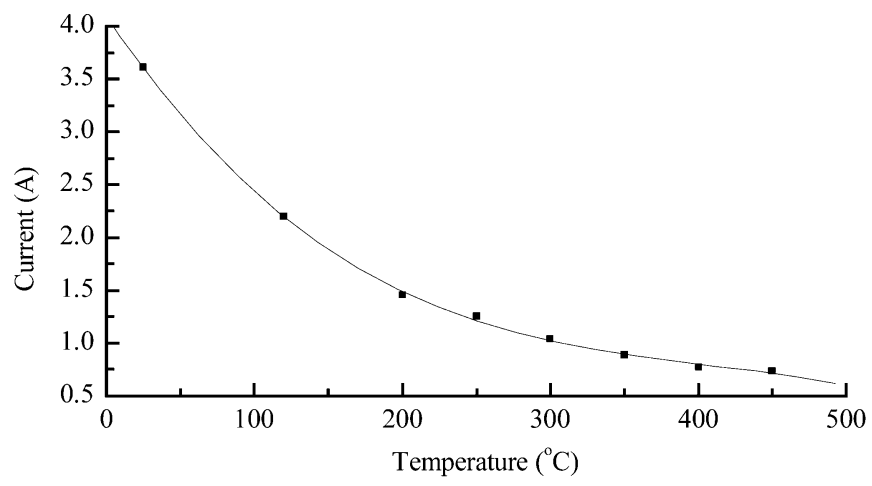

(b)

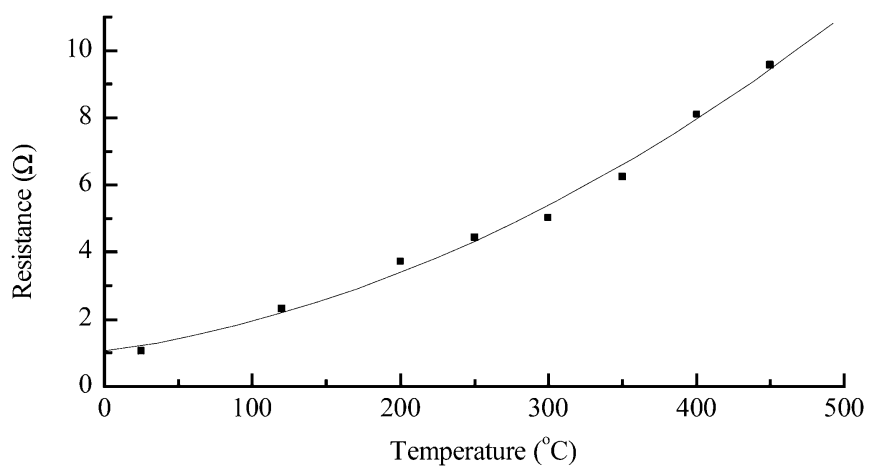

(c)

Fig. 4. Temperature dependency of the dc characteristics of the SiC JFET for the "ON" condition. (a) $\mathrm{V}_{\mathrm{ds}}-\mathrm{I}_{\mathrm{ds}}$ characteristics for $\mathrm{V}_{\mathrm{gs}}=0 \mathrm{~V}$, (b) saturation current $I_{d s}$ for $V_{d s}=20 \mathrm{~V}$, (c) drain-source resistance for $I_{d s}=0.5 \mathrm{~A}$.

much smaller than that of the SiC JFET. Fig. 5(c) shows that the reverse leakage current of the $\mathrm{SiC}$ SBD increases significantly when the temperature exceeds $300{ }^{\circ} \mathrm{C}$. The reverse voltage capability decreases from $660 \mathrm{~V}$ at $25{ }^{\circ} \mathrm{C}$ to $100 \mathrm{~V}$ at 400 ${ }^{\circ} \mathrm{C}$. This is very important for the designer because the SBD is subjected to a reverse voltage equal to the converter input voltage.

\section{DC-DC BUCK CONVERTER OPERATION UNDER HIGH TEMPERATURE CONDITIONS}

\section{A. Experimental Setup}

Fig. 6 illustrates the experimental setup for measuring the performance of the SiC-based dc-dc buck converter. Only the SiC JFET, SBD and inductor are exposed to ambient temperature variations in the oven since high-temperature capacitors and 


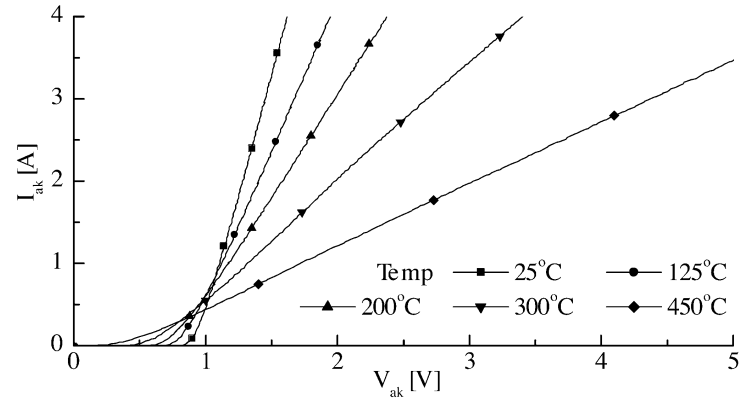

(a)

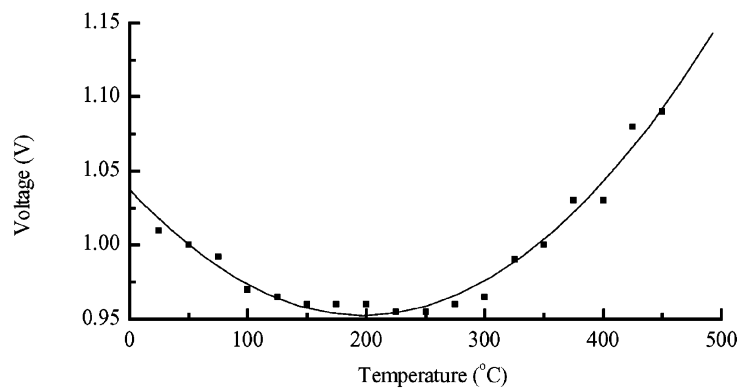

(b)

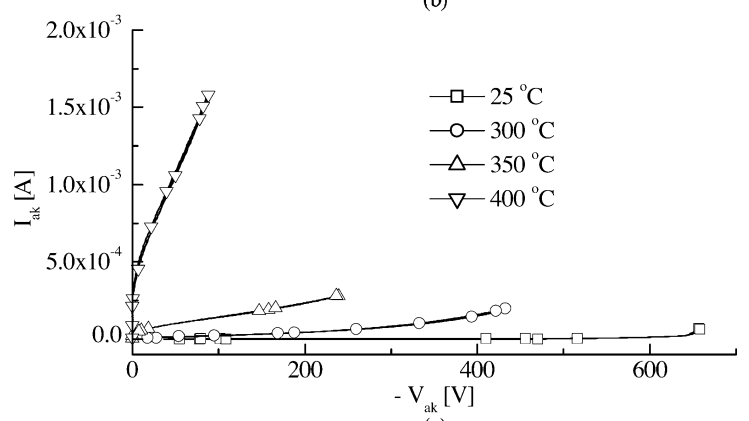

(c)

Fig. 5. Temperature dependency of the dc characteristics for the SiC SBD. (a) $\mathrm{V}_{\mathrm{ak}}-\mathrm{I}_{\mathrm{ak}}$ characteristics, (b) forward voltage drop $\left(\mathrm{V}_{\mathrm{ak}}\right)$ for $\mathrm{I}_{\mathrm{ak}}=0.5 \mathrm{~A}$, (c) reverse leakage and break down characteristics.

gate drivers were not available to the research team. The effects of some parasitic inductance are noticeable in the measurement results since the measurements were performed outside of the oven through relatively long wires. The converter operated at a $100 \mathrm{kHz}$ switching frequency with $50 \%$ duty cycle, $100 \mathrm{~V} \mathrm{dc}$ input voltage and a $100 \Omega$ load resistance. The voltage is determined from the forward blocking voltage limitation of the JFET and the reverse voltage limitation of the SBD at high ambient temperatures. As mentioned above, the rated output current was set to $0.5 \mathrm{~A}$ for the considered ambient temperature range from $25^{\circ} \mathrm{C}$ to $400^{\circ} \mathrm{C}$. The gate driver voltage applied to the SiC JFET is $V_{\mathrm{gs}}=0 \mathrm{~V}$ for the "ON" condition and $V_{\mathrm{gs}}=-18 \mathrm{~V}$ for the "OFF" condition, which is lower than the threshold gate voltage of $-15 \mathrm{~V}$ at $450{ }^{\circ} \mathrm{C}$.

Fig. 7 gives the voltage and current waveforms of the converter for comparing $\mathrm{SiC}$ and $\mathrm{Si}$ devices. The oven was not used so the voltage and current waveforms were measured with probes connected directly to the circuit minimizing parasitic components in the power stage and measurement circuit as much as possible. Sharp switching waveforms with small ringing are observed. The switching performance of the two FETs almost coincide, but the Si fast recovery diode (FRD)

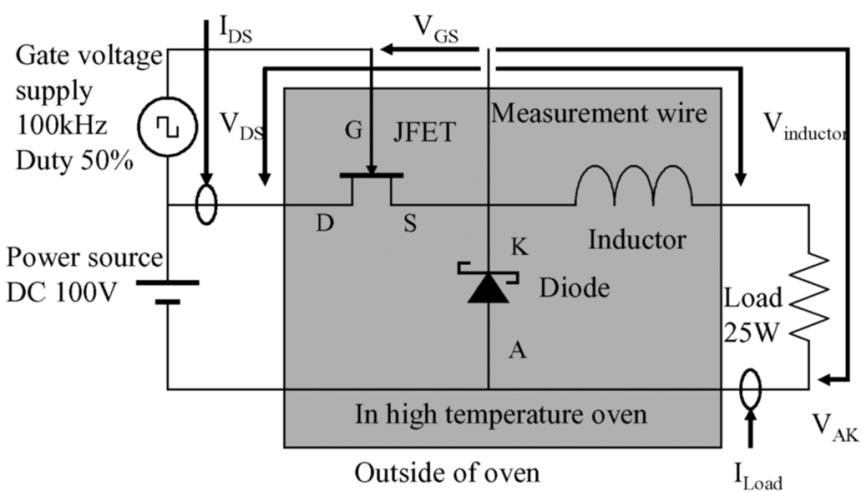

Fig. 6. Experimental setup for extremely high temperature operation of the SiC dc-dc buck converter.

shows a larger reverse recovery current than the SiC SBD at the turn on of the FET, as expected. This illustration demonstrates the superior characteristics of SiC SBD even at room temperature.

\section{B. Switching Characteristics of SiC Devices Under High Ambient Temperatures}

Fig. 8 shows the measured voltage and current waveforms of the dc-dc buck converter as function of ambient temperature. Fig. 8(a) shows the drain-source voltage $V_{\mathrm{ds}}$ for the SiC JFET indicating that it can remain in the "OFF" condition when applying a gate voltage $V_{\text {gs }}$ of $-18 \mathrm{~V}$ for a $V_{\mathrm{ds}}$ of 100 $\mathrm{V}$ regardless of the ambient temperature. The drain-source voltage drop during the "ON" condition increases at higher ambient temperatures. The $5 \mathrm{~V}$ drop at $400{ }^{\circ} \mathrm{C}$ coincides with the results from the dc characteristic in Fig. 4. The damping of the switching transients becomes more pronounced as the drain-source resistance increases (conduction loss). Fig. 8(b) shows the drain current response of the SiC JFET, which shows no reverse recovery or tail current. The turn-on behavior of the SiC JFET is affected by the switching behavior of the SiC SBD while the turn-off behavior is dominated by the SiC JFET itself. The latter retains its high-speed switching capability up to an extremely high ambient temperature of $400{ }^{\circ} \mathrm{C}$. The $d i / d t$ of the drain current does not change with temperature, i.e., $-1.45 \times ; 10^{7} \mathrm{~A} / \mathrm{s}$ at $25{ }^{\circ} \mathrm{C}$ versus $-1.44 \times ; 10^{7} \mathrm{~A} / \mathrm{s}$ at $400{ }^{\circ} \mathrm{C}$. The peak value of the transient current at the turn-on instant decreases with increasing ambient temperatures, but it exceeds the saturated drain current of the SiC JFET (i.e., a peak current of $1.2 \mathrm{~A}$ and a saturated current of $0.7 \mathrm{~A}$ for the $400{ }^{\circ} \mathrm{C}$ case). The reduction of the peak value in the transient current with rising temperatures results in a reduction of the saturated drain current with the excess current attributed to circuit parasitic capacitance components.

Fig. 8(c) shows the anode-cathode voltage of the SiC SBD. The imposed voltage during the non-conduction interval decreases a few Volts at high temperatures because the voltage drop across the SiC JFET increases with increasing ambient temperatures. Fig. 8(d) displays the current flowing through the SiC SBD that turns on quickly when commutating current from the $\mathrm{SiC}$ JFET, and has a fairly small forward recovery accompanied by small oscillations as shown in Fig. 8(c). In contrast, it 


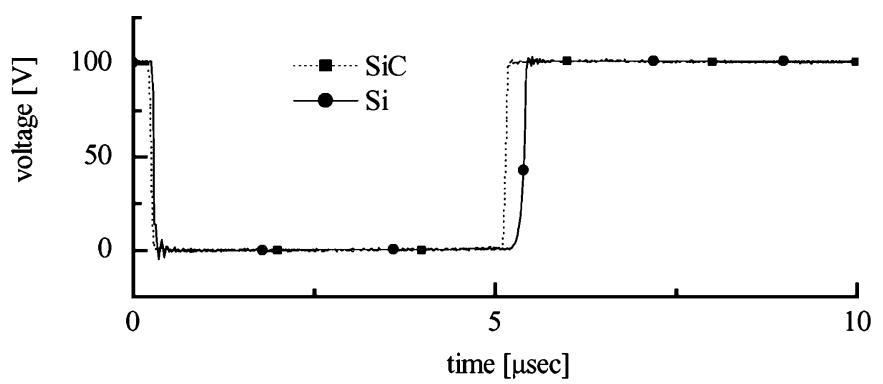

(a)

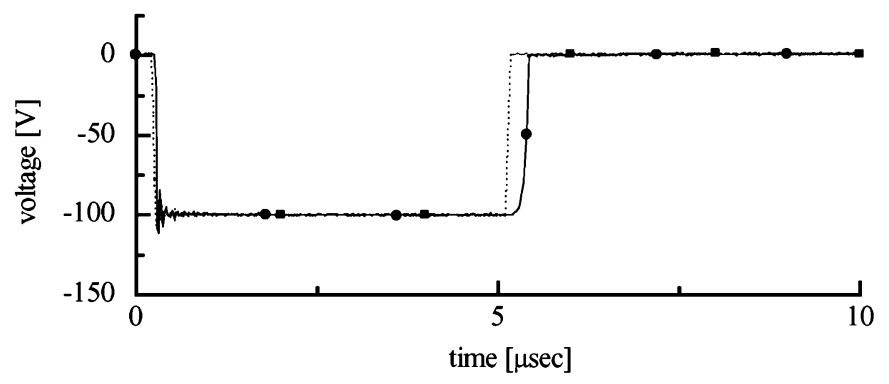

(c)

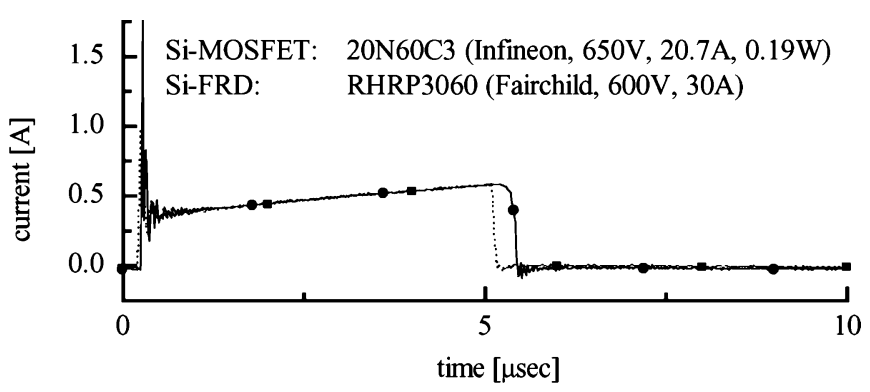

(b)

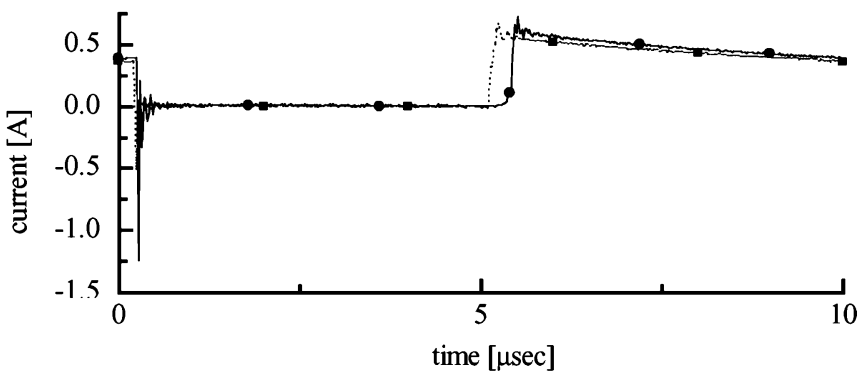

(d)

Fig. 7. Comparison between $\mathrm{SiC}$ devices and $\mathrm{Si}$ devices at room temperature $\left(25^{\circ} \mathrm{C}\right)$. (a) $\mathrm{V}_{\mathrm{ds}}(\mathrm{SiC}-\mathrm{JFET} / \mathrm{Si}-\mathrm{MOSFET})$, (b) $\mathrm{I}_{\mathrm{ds}}(\mathrm{SiC}-\mathrm{JFET} / \mathrm{Si}-\mathrm{MOSFET})$, (c) $\mathrm{V}_{\mathrm{ak}}(\mathrm{SiC}-\mathrm{SBD} / \mathrm{Si}-\mathrm{FRD})$, (d) $\mathrm{I}_{\mathrm{ak}}(\mathrm{SiC}-\mathrm{SBD} / \mathrm{Si}-\mathrm{FRD})$.

produces a relatively large reverse current at turn off. Even though the wires for connecting the devices are relatively long (resulting in some parasitic inductances), such a spike current is not observed during the turn-on of the diode. So, this behavior cannot be attributed entirely to parasitic inductances. Furthermore, the SiC SBD does not produce reverse recovery current by carrier recombination and the turn-on speed of the SiC JFET is quite fast resulting in a large $d v / d t$. The displacement current, which charges the capacitance between the anode and cathode of the diode, then becomes predominant [1], [3]. Since the amplitude of the reverse displacement current does not change with temperature, it can be said that the switching speed does not deteriorate with temperature rise. The oscillations are caused by the displacement current during the diode turn off decay, and have large amplitudes for about 2 cycles.

Fig. 8(e) shows the load voltage whose average value is about $50 \mathrm{~V}$, which agrees with the set operating condition of $100 \mathrm{~V}$ input voltage and $50 \%$ duty cycle. This waveform also shows the effect of not having an output filter capacitor. The converter operates normally from room temperature to an extremely high ambient temperature of $400{ }^{\circ} \mathrm{C}$. The output voltage decreases approximately by $5 \mathrm{~V}$ at $400{ }^{\circ} \mathrm{C}$ from its value at room temperature, but the reduction is relatively small for high output voltages. This is not the case for low output voltages (e.g., $<5 \mathrm{~V})$.

Fig. 9(a) gives the conversion efficiency of the buck converter related to ambient temperature. The efficiency is almost $82 \%$ at room temperature, and changes only a small percentage with temperature rise. Hence, it can be said that the influence of the temperature variation is not significant to the power conversion efficiency in this converter configuration. Fig. 9(b) shows the temperature dependency of the averaged converter output voltage for one switching period. The average output voltage at $400{ }^{\circ} \mathrm{C}$ drops $3 \mathrm{~V}$ from the value at room temperature. This reduction almost coincides with the $5 \mathrm{~V}$ increase of the drain-source voltage drop due to temperature as shown in Fig. 4(a) and taking into account the 50\% JFET duty cycle for the "ON" condition. The spike voltages and currents observed at the top and bottom of the waveform in Fig. 8(b), (d), and (e) are caused by the switching operations of the SiC JFET and SBD as well as the parasitic components from the long wires used for the main circuit and the measurements. The ringing waveform difference between Figs. 7 and 8 indicates the existence of the considerable parasitic for high-temperature measurements. The given waveforms of the output voltage maintain the expected shape for all considered temperatures. This means that the inductance of the inductor is not greatly affected within the considered temperature range. The normal operation of the inductor as temperature changes can also be confirmed from the output load current shown in Fig. 8(f). The operation of this passive component under extremely high temperature conditions is satisfactory. The main disadvantage is that its volume is approximately $230 \mathrm{~cm}^{2}$ which is very large when compared to an inductor with similar ratings operating at room temperature. The inductor size can be reduced by increasing the switching frequency further and using a coreless inductor.

Fig. 9(c) and (d) shows the peak switching loss power of the SiC JFET and SBD, respectively. The peak switching loss of the SiC JFET increases with temperature rise, and it becomes 1.6 times at $400{ }^{\circ} \mathrm{C}$ of the value at room temperature. On the contrary, the peak switching loss of the SiC SBD decreases with temperature rise, and it becomes half at 400 ${ }^{\circ} \mathrm{C}$ of the value at room temperature. These switching loss characteristics cannot be estimated from the obtained static IV characteristics in Figs. 3-5.

The results indicate that the switching speed of the SiC JFET is excellent, and the turn-on speed of the SiC JFET must be 


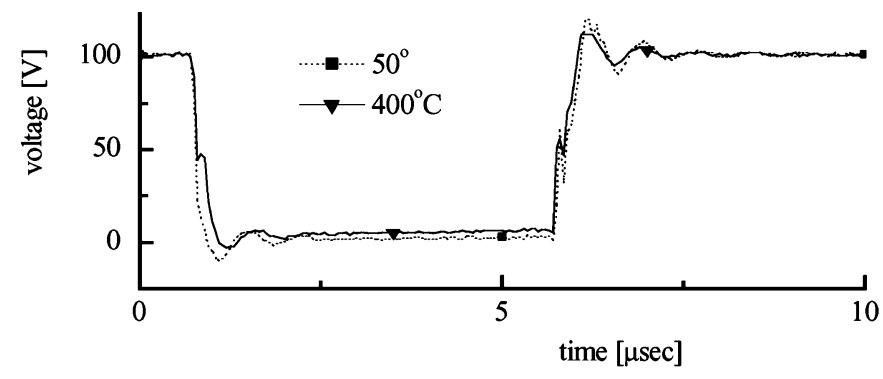

(a)

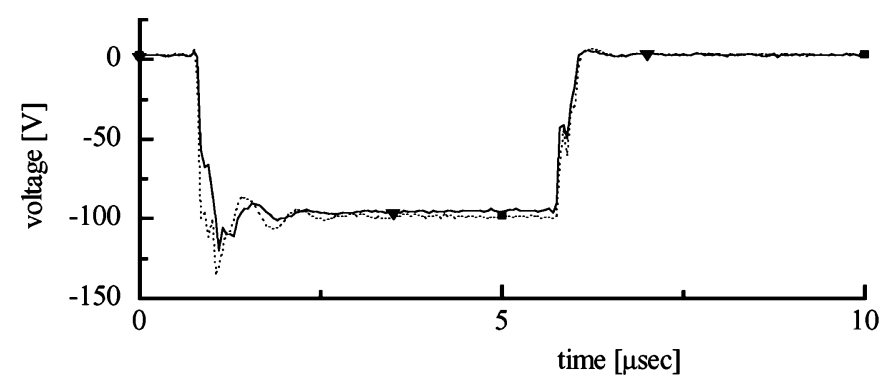

(c)

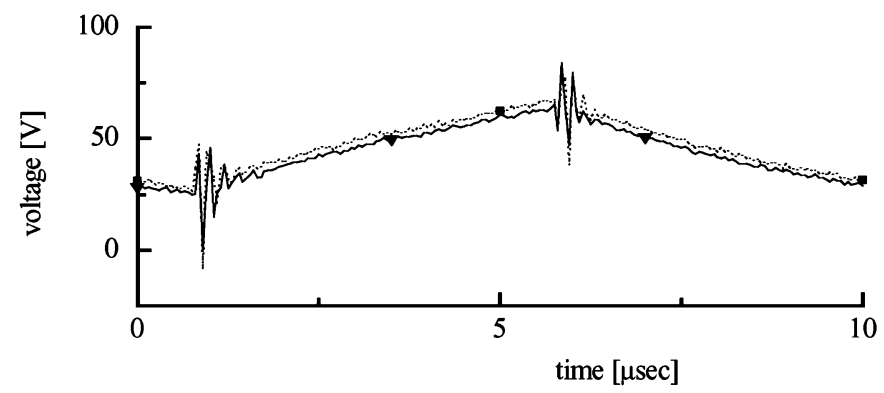

(e)

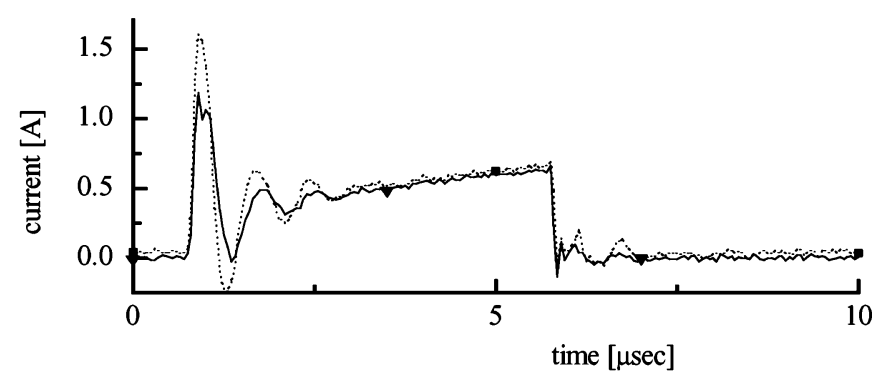

(b)

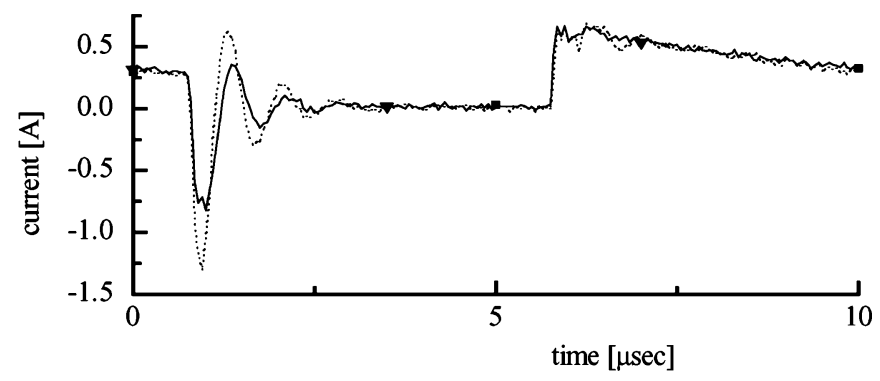

(d)

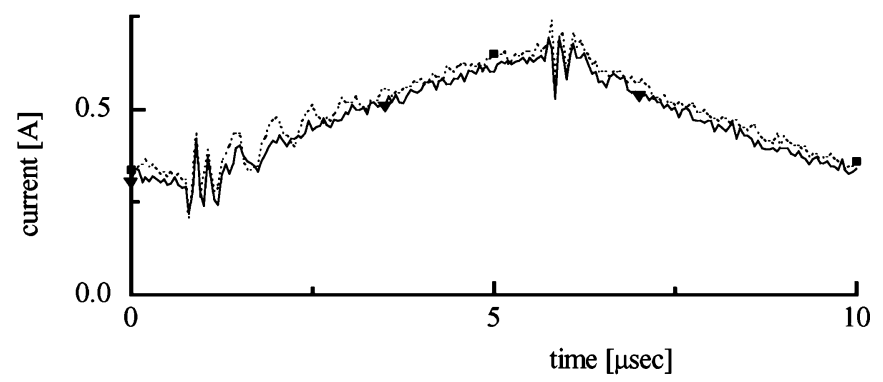

(f)

Fig. 8. Experimental results of the SiC-based dc-dc buck converter. (a) $\mathrm{V}_{\mathrm{ds}}$ (JFET), (b) $\mathrm{I}_{\mathrm{ds}}$ (JFET), (c) $\mathrm{V}_{\mathrm{ak}}$ (SBD), (d) $\mathrm{I}_{\mathrm{ak}}$ (SBD), (e) load voltage, (f) Load current.

reduced to cope with the SiC SBD switching characteristics to prevent transient ringing and undue derating of the SiC JFET.

\section{CONCLUSION}

This paper investigated the static and transient characteristics of SiC JFET and SiC SBD under a wide range of ambient temperatures. The conventional plastic package cannot be exposed to such high temperatures; therefore $\mathrm{SiC}$ bare die were packaged into thermally stable packages. The packaged SiC JFET and SBD were evaluated over a wide range of ambient temperatures. The measured dc characteristic results indicated that the available current ratings of the SiC JFET decreased with increasing temperatures with the current rating becoming $20 \%$ at $450{ }^{\circ} \mathrm{C}$ with respect to room temperature. The threshold gate voltage was slightly lower with increasing ambient temperatures $(-15$ $\mathrm{V}$ to $-20 \mathrm{~V}$ ). However, it can be easily managed by offsetting the gate voltage a few Volts higher (in the negative direction). The measured dc characteristics of the SiC SBD also showed an increasing series resistance with temperature rise. But, the forward voltage drop also interacts with the cut-in voltage drop with temperature rise. As a result, it showed non-monotonic changes with increasing temperatures.

A dc-dc buck converter for extremely high temperature operation using SiC JFET, SiC SBD (both in thermally stable packages) and a high-temperature inductor was designed by taking into account the drain current rating reduction of the SiC JFET at high temperatures. The operation of the devices were confirmed and evaluated for the converter operating from $25^{\circ} \mathrm{C}$ (room temperature) to extremely high ambient temperatures $\left(\sim 400^{\circ} \mathrm{C}\right)$. Although the drain-source resistance increased and the power conversion efficiency deteriorated with temperature, this reduction of the conversion efficiency was not very significant and the increase in the voltage drop between the drain and the source was relatively small in comparison to the converter output voltages (this would not be the case for buck converters with output voltages under $5 \mathrm{~V}$ ). The superior switching characteristics of a SiC JFET were experimentally observed within the considered temperature range. The results showed that the inductive switching characteristics of the SiC JFET and SBD hardly deteriorated with increasing temperatures. However, the very fast turn-on operation of the SiC JFET induced reverse displacement currents in the $\mathrm{SiC}$ SBD. Therefore, this issue must be addressed in the design of the gate driver circuit. The discriminative tradeoffs in designing this converter for high temperature operation is summarized in Table III.

In closing, these devices are very suitable for high temperature operation. This ability of SiC devices for extremely high temperature operation indicates that they hold promise for many applications in aerospace and deep space missions. 


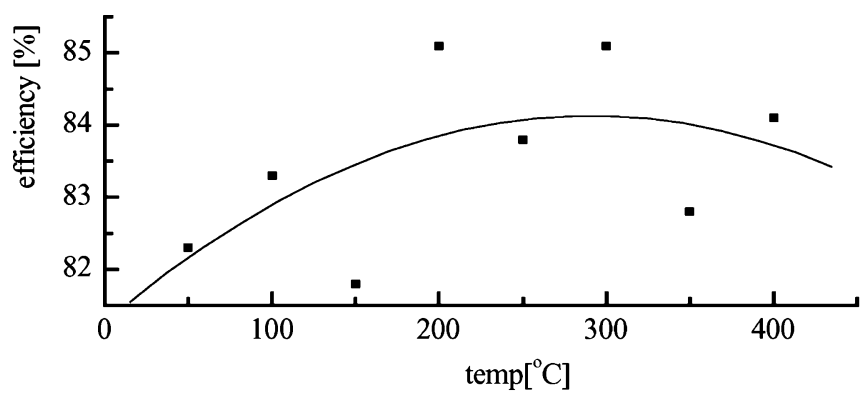

(a)

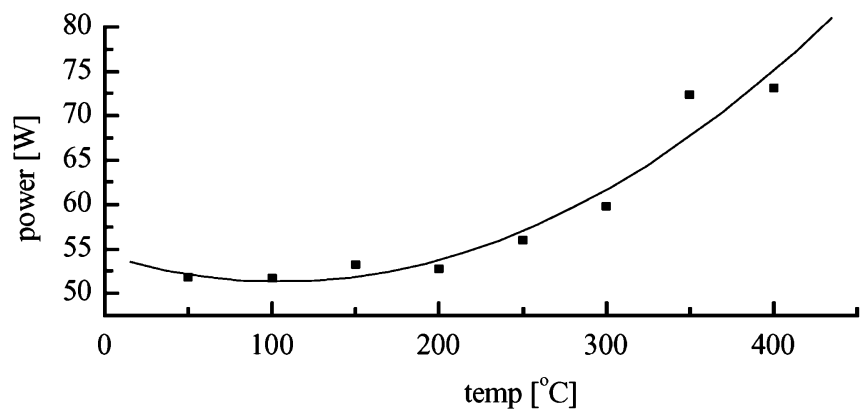

(c)

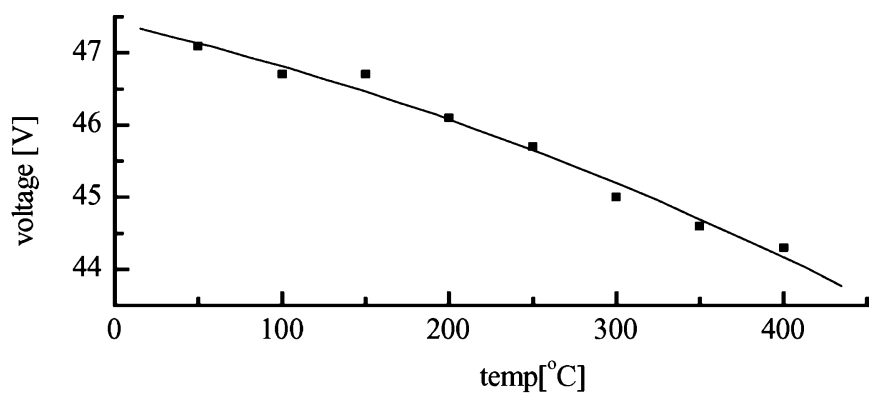

(b)

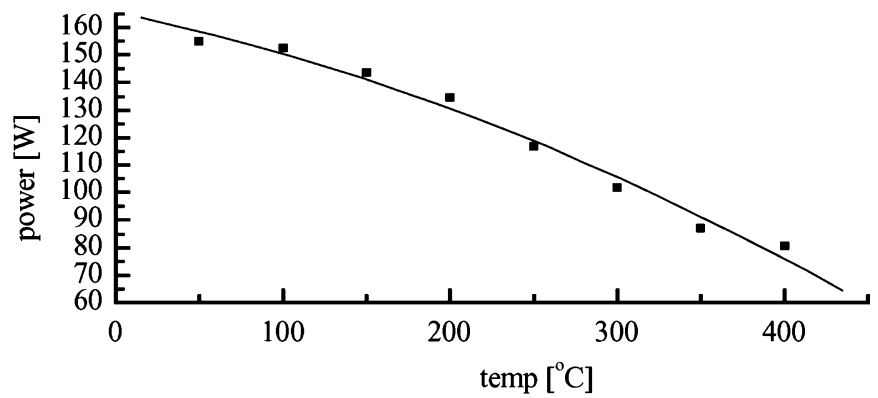

(d)

Fig. 9. Temperature dependency in the performance of SiC-based dc-dc buck converter. (a) conversion efficiency, (b) averaged output voltage, (c) peak switching loss of JFET at turn off, (d) peak switching loss of SBD at turn off.

TABLE III

Tradeoffs in Designing High TeMPERATURe CONVERTER

\begin{tabular}{|c|c|}
\hline SiC JFET & $\begin{array}{l}\text { Reduction in current ratings } \\
\text { Reduction in blocking voltage }\end{array}$ \\
\hline Shottky diode & $\begin{array}{l}\text { Increment in reverse leakage } \\
\text { current }\end{array}$ \\
\hline
\end{tabular}

\section{ACKNOWLEDGMENT}

Dr. Funaki greatly acknowledges the support for this research from the Kyoto University Venture Business Laboratory. The authors acknowledge the SiC JFET devices supplied by Dr. P. Friedrichs (SiCED) and the experimental facilities by Dr. A. Lostetter, Arkansas Power Electronics International, Inc.

\section{REFERENCES}

[1] J. L. Hudgins, G. S. Simin, E. Santi, and M. A. Khan, "An assessment of wide bandgap semiconductors for power devices," IEEE Trans. Power Elect., vol. 18, no. 3, pp. 907-914, 2003.

[2] M. Lades, "Modeling and Simulation of Wide Bandgap Semiconductor Devices: 4H/6H-SiC," in Selected Topics of Electronics and Micromechatronics. Aachen: Shaker Verlag, 2002, vol. 3.

[3] A. R. Hefner, R. Singh, J. Lai, D. Berning, S. Bouche, and C. Chapuy, "SiC power diodes provide breakthrough performance for a wide range of applications," IEEE Trans. Power Elect., vol. 16, no. 2, pp. 273-280, 2001.

[4] G. Spiazzi, S. Buso, M. Citron, M. Corradin, and R. Pierobeon, "Performance evaluation of a schottky $\mathrm{SiC}$ power diode in a boost $\mathrm{PFC}$ application," IEEE Trans. Power Elect., vol. 18, no. 6, pp. 1249-1253, 2003.

[5] J. Richmond, S. Ryu, M. Das, and S. Krishnaswami, "An overview of cree silicon carbide power devices," presented at the IEEE Workshop on Power Electronics in Transportation, Oct. 21-22, 2004.

[6] T. R. McNutt, A. R. Hefner, H. A. Mantooth, J. Duliere, D. W. Berning, and R. Singh, "Silicon carbide PiN and merged PiN Schottky power diode models implemented in the saber circuit simulator," IEEE Trans. Power Elect., vol. 19, no. 3, pp. 573-581, 2004.

[7] A. M. Abou-Alfotouh, A. V. Radun, H. R. Chang, and C. Winterhalter, "A 1-MHz hard-switched silicon carbide DC-DC converter," IEEE Trans. Power Elect., vol. 21, no. 4, pp. 880-889, 2006.
[8] D. B. Slater, L. A. Lipkin, G. M. Johnson, A. V. Suvorov, and J. W. Palmour:, "High temperature enhancement-mode NMOS and PMOS devices and circuits in 6H-SiC," 53rd Device Research Conf., pp. 100-101, Jun. 19-21, 1995.

[9] J. B. Casady, W. C. Dillard, R. W. Johnson, and U. Rao, "A hybrid $6 \mathrm{H}-\mathrm{SiC}$ temperature sensor operational from $25^{\circ} \mathrm{C}$ to $500^{\circ} \mathrm{C}$," IEEE Trans. Compon., Packaging, and Manufacturing Technology, vol. 19, no. 3, pp. 16-422, 1996.

[10] C. J. Scozzie, C. W. Tipton, W. M. DeLancey, J. M. McGarrity, and F. B. McLean, "High temperature stressing of SiC JFETs at $300^{\circ} \mathrm{C}$," in Proc. 32nd Int. Reliability Physics Symp., Apr. 11-14, 1994, pp. 351-358.

[11] B. Ray and R. L. Spyker, "High temperature design and testing of a DC-DC power converter with $\mathrm{Si}$ and $\mathrm{SiC}$ devices," in Proc. 39th IEEE Industry Applications Society Annu. Meeting, Seattle, WA, Oct. 3-7, 2004, 33p5.

[12] B. Ray, J. D. Scofield, R. L. Spyker, B. Jordan, and S. H. Ryu, "High temperature operation of a DC-DC power converter utilizing SiC power devices," presented at the 20th IEEE Applied Power Electronics Conf., Austin, TX, Mar. 6-10, 2005, Session 8.2.

[13] M. S. Chinthavali, B. Ozpineci, and L. M. Tolbert, "High temperature characterization of $\mathrm{SiC}$ power electronic devices," presented at the 2004 IEEE Workshop on Power Electronics in Transportation, Oct. 21-22, 2004, Sheraton Detroit Novi, Detroit, MI.

[14] R. L. Kelley, M. S. Mazzola, W. A. Draper, and J. Casady, "Inherently safe DC/DC converter using a normally-on SiC JFET," in Proc. 20th IEEE Applied Power Electronics Conf., Mar. 6-10, 2005, pp. $1561-1565$.

[15] B. Ozpineci and L. M. Tolbert, "Characterization of SiC schottky diodes at different temperatures," IEEE Power Elect. Lett., vol. 1, no. 2, pp. 54-57, 2003.

[16] J. HornbergerE. S. CilioR. M. SchupbachH. A. Mantooth,A. B. Lostetter, "A high-temperature multichip power module (MCPM) inverter utilizing silicon carbide $(\mathrm{SiC})$ and silicon on insulator (SOI) electronics," in Proc. IEEE 37th Annu. Power Electronics Specialists Conf., Jeju, Korea, Jun. 18-22, 2006, pp. 9-15, (Plenary Session1-2)

[17] P. Friedrchs, H. Mitlehner, R. Kaltschmidt, U. Weinert, W. Bartsch, C. Hech, K. O. Dohnke, B. Weis, and D. Stephani, "Static and dynamic characteristics of $4 \mathrm{H}-\mathrm{SiC}$ JFETs designed for different blocking categories," Mat. Sci. Forum, vol. 338-342, pp. 1243-1246, 2000.

[18] P. Friedrchs, H. Mitlehner, R. Schorner, K. O. Dohnke, R. Elpelt, and D. Stephani, "Application-Oriented unipolar switching SiC devices," Mat. Sci. Forum, vol. 389-393, pp. 1185-1190, 2000. 
Tsuyoshi Funaki (M'00) received the B.E. and M.E. degrees in electrical engineering and the Ph.D. degree all from Osaka University, Osaka, Japan.

He joined Osaka University as an Research Associate in 1994 and became an Assistant Professor in 2001. In 2002, he joined Kyoto University, Kyoto, Japan, as an Associate Professor. He was a Visiting Scholar in the Electrical Engineering Department, University of Arkansas, Fayetteville, in 2004 and 2005, where he did collaborative research on $\mathrm{SiC}$ device and its application.

Dr. Funaki is a member of the Institute of Electrical Engineers of Japan (IEEJ), the Institute of Electronics, Information and Communication Engineers (IEICE) of Japan, the Institute of Systems, Control and Information Engineers (ISCIE), Society of Atmospheric Electricity of Japan (SAEJ), and the Institution of Engineering and Technology (IET), London, U.K.

Juan Carlos Balda (M'78-SM'94) was born in Bahía Blanca, Argentina. He received the B.Sc. degree in electrical engineering from the Universidad Nacional del Sur, Bahía Blanca, Argentina, in 1979, and the Ph.D. degree in electrical engineering from the University of Natal, Durban, South Africa, in 1986.

In 1979, he worked for two and one-half years at Hidronor S.A., an electric utility in the Southwestern part of Argentina. He was employed as a Researcher and a part-time Lecturer at the University of Natal until July 1987. He then spent two years as a visiting Assistant Professor at Clemson University, Clemson, SC. He has been at the University of Arkansas, Fayetteville, since July 1989 where he is currently a Full Professor and Associate Department Head. His main research interests are power electronics, electric power distribution systems, motor drives and electric power quality.

Dr. Balda is a member of the Power Electronics and Industry Applications Societies, and the honor society Eta Kappa Nu. He is a counselor of the IEEE Student branch and a Faculty Advisor to the Ham Radio Club at the University of Arkansas.

Jeremy Junghans (S'03-M'07) is currently pursuing the M.S.E.E. degree at the University of Arkansas, Fayetteville.

$\mathrm{He}$ is currently working as the Principle Product, Packaging and Assembly Engineer for the RF Power Devices Group at Northrop Grumman Electronic Systems in Baltimore, MD. His responsibilities include modeling and simulation of packaged transistors, design of packaging layouts including internal matching networks and oversight of production assembly of high frequency power devices. His previous research includes the spray cooling of power electronics, fabrication and packaging of silicon carbide $(\mathrm{SiC})$ devices and the production of multilayer circuits using low temperature cofired ceramics (LTCC).

Mr. Junghans previously served as the Vice-President of the IEEE CPMT Society and President of the International Microelectronics and Packaging Society student chapters.

Avinash S. Kashyap (S'03) was born in Thrissur, India, on October 14, 1979. $\mathrm{He}$ received the B.Tech degree in electrical and electronics engineering from the University of Calicut, India, in 2001 and the M.S. degree in electrical engineering from the University of Arkansas, Fayetteville, in 2005 where he is currently pursuing the Ph.D. degree in electrical engineering.

His research interests include the design, modeling and fabrication of silicon carbide $(\mathrm{SiC})$ devices. He has previously interned at the Oak Ridge National Laboratory's wide bandgap research group at Knoxville, TN, and the SPICE modeling group of National Semiconductor at Santa Clara, CA.

Mr. Kashyap is a recipient of the Sam Walton Doctoral Academy Fellowship and the William E. Clark Endowed Doctoral Fellowship.

H. Alan Mantooth (S'83-M'90-SM'97) received the B.S. (summa cum laude) and M. S. degrees in electrical engineering from the University of Arkansas (UA), Fayetteville, in 1985 and 1987, respectively, and the Ph.D. degree from the Georgia Institute of Technology, Atlanta, in 1990.

He joined Analogy in 1990 where he focused on semiconductor device modeling and the research and development of HDL-based modeling tools and techniques. Besides modeling, his interests include analog and mixed-signal IC design. In 1996, he was named a Distinguished Member of Technical Staff at Analogy (now owned by Synopsys). In 1998, he joined the faculty of the Department of Electrical Engineering at the UA, as an Associate Professor and was promoted to his present rank of Full Professor in 2002. In 2003, he co-founded
Lynguent, an EDA company focused on modeling and simulation tools. He established the National Center for Reliable Electric Power Transmission at the UA in 2005, for which he serves as Director. He has published over 100 articles on models, modeling techniques, and modeling strategies. He holds patents on software architecture and algorithms for modeling tools and has others pending. He is coauthor of the book Modeling with an Analog Hardware Description Language (Kluwer Academic, 1995).

Dr. Mantooth is a member of Tau Beta Pi and Eta Kappa Nu. He was selected to the Georgia Tech Council of Outstanding Young Engineering Alumni in 2002 and has received a teaching, service, and/or research award every year since returning to the UA. In 2006, he was selected as the inaugural holder of the 21s Century Chair in Mixed-Signal IC Design and CAD, an endowed chair position. He has served on several technical program committees for IEEE conferences He was the Technical Program Chair for the IEEE International Workshop on Behavioral Modeling and Simulation (BMAS) in 2000 and General Chair in 2001. He served as Guest Editor for a Special Issue on Behavioral Modeling and Simulation for the IEEE TRANSACTIONS ON COMPUTER-AIDED DESIGN in February 2003 and as an IEEE Circuits and Systems Society Distinguished Lecturer in 2003-2004. He is currently serving the profession in the following roles: 1) IEEE CAS representative on the Design Automation Conference Executive Committee, 2) Member of the IEEE Council on Electronic Design Automation, and 3) Member of the Power Electronics Society Advisory Committee as Chair of the Society's Standards Committee.

Fred Barlow (M'96) received the B.S. degree in physics and applied physics from Emory University, Atlanta, GA and the M.Sc. and Ph.D. degrees in electrical engineering from the Virginia Polytechnic Institute and State University (Virginia Tech), Blacksburg.

He is currently working as an Associate Professor in the Electrical and Computer Engineering Department at the University of Idaho, Moscow, with an emphasis on electronic packaging. He has published widely on electronic packaging and electronic materials evaluation and is a coeditor of The Handbook of Thin Film Technology (McGraw Hill, 1998), as well as the Handbook of $\mathrm{Ce}$ ramic Interconnect Technology (CRC Press, 2007).

Dr. Barlow is a senior member of the International Microelectronics and Packaging Society (IMAPS). He also serves as the Editor-in-Chief of the Journal of Microelectronics and Electronic Packaging.

Tsunenobu Kimoto (M'00) received the B.E. and M.E. degrees in electrical engineering and the Ph.D. degree (based on his work on SiC epitaxial growth, material characterization, and high-voltage diodes) in 1996, all from Kyoto University, Kyoto, Japan, in 1986, 1988, and 1996, respectively.

He joined Sumitomo Electric Industries, Ltd., in April 1988, where he conducted research on amorphous-Si solar cells and semiconducting diamond material for high-temperature devices. In 1990, he started $\mathrm{SiC}$ research work as a Research Associate at Kyoto University. From September 1996 through August 1997, he was a Visiting Scientist at Linköping University, Linköping, Sweden, where he was involved in fast epitaxy of $\mathrm{SiC}$ and high-voltage Schottky diodes. $\mathrm{He}$ is currently a Professor in the Department of Electronic Science and Engineering, Kyoto University. He has published over 200 papers in scientific journals and international conference proceedings. His main research activity includes $\mathrm{SiC}$ epitaxial growth, optical and electrical characterization, ion implantation, MOS physics, and high-voltage diodes and transistors.

Takashi Hikihara (S'84-M' 88) was born in Kyoto, Japan, in 1958. He received the B.E. degree from Kyoto Institute of Technology, Kyoto, Japan, in 1982, and the M.E., and Ph.D. degrees from Kyoto University, Kyoto, Japan, in 1984, and 1990 , respectively.

From 1987 to 1997, he was with the faculty of the Department of Electrical Engineering, Kansai University, Osaka, Japan. From 1993 to 1994, he was a Visiting Researcher at Cornell University. In 1997, he joined the Department of Electrical Engineering, Kyoto University, American Physics Society (APS), Society for Industrial and Applied Mathematics (SIAM), and so on. where he is currently a Professor. His research interests include nonlinear science and its application. He is also interested in system control and nanotechnology.

Dr. Hikihara is a member of the Institution of Engineering and Technology (IET), London, U.K., the Institute of Electronics, Information and Communication Engineers (IEICE) of Japan, The Institute of Electrical Engineers of Japan (IEEJ), the American Physics Society (APS), the Society for Industrial and Applied Mathematics (SIAM), and so on. He was an Associate Editor for the Transactions of the IEICE, the IEEJ, and others. He is currently an Associate Editor of the Journal of Circuits, Systems, and Computers. 